\section{(6) OPEN ACCESS}

\title{
Impact of low-dose CT screening on smoking cessation among high-risk participants in the UK Lung Cancer Screening Trial
}

\author{
Kate Brain, ${ }^{1}$ Ben Carter, ${ }^{1,2}$ Kate J Lifford, ${ }^{1}$ Olivia Burke, ${ }^{1}$ Anand Devaraj, ${ }^{3}$ \\ David R Baldwin, ${ }^{4}$ Stephen Duffy, ${ }^{5}$ John K Field ${ }^{6}$
}

- Additional material is published online only. To view please visit the journal online (http://dx.doi.org/10.1136/ thoraxjn-2016-209690)

For numbered affiliations see end of article.

Correspondence to Dr Kate Brain, Division of Population Medicine, School of Medicine, Cardiff University, Heath Park, Cardiff CF14 4YS, UK; brainke@cardiff.ac.uk

Received 4 November 2016 Revised 7 February 2017 Accepted 27 February 2017 Published Online First 1 September 2017

\section{SLinked}

- http://dx.doi.org/10.1136/ thoraxjnl-2017-210621

CrossMark

To cite: Brain K, Carter B, Lifford KJ, et al. Thorax 2017;72:912-918.

\section{ABSTRACT}

Background Smoking cessation was examined among high-risk participants in the UK Lung Cancer Screening (UKLS) Pilot Trial of low-dose CT screening.

Methods High-risk individuals aged $50-75$ years who completed baseline questionnaires were randomised to CT screening (intervention) or usual care (no screening control). Smoking habit was determined at baseline using self-report. Smokers were asked whether they had quit smoking since joining UKLS at $\mathrm{T}_{1}$ (2 weeks after baseline scan results or control assignment) and $T_{2}$ (up to 2 years after recruitment). Intention-to-treat (ITT) regression analyses were undertaken, adjusting for baseline lung cancer distress, trial site and sociodemographic variables.

Results Of a total 4055 individuals randomised to CT screening or control, 1546 were baseline smokers (759 intervention, 787 control). Smoking cessation rates were $8 \%$ (control $n=36 / 479$ ) versus $14 \%$ (intervention $n=75$ / 527 ) at $T_{1}$ and $21 \%$ (control $n=79 / 377$ ) versus $24 \%$ (intervention $n=115 / 488$ ) at $T_{2}$. ITT analyses indicated that the odds of quitting among screened participants were significantly higher at $\mathrm{T}_{1}$ (adjusted $\mathrm{OR}(\mathrm{aOR}) 2.38$, $95 \% \mathrm{Cl} 1.56$ to $3.64, \mathrm{p}<0.001)$ and $\mathrm{T}_{2}$ (aOR 1.60, $95 \% \mathrm{Cl} 1.17$ to $2.18, \mathrm{p}=0.003$ ) compared with control. Intervention participants who needed additional clinical investigation were more likely to quit in the longer term compared with the control group (aOR $2.29,95 \% \mathrm{Cl}$ 1.62 to $3.22, p=0.007$ ) and those receiving a negative result (aOR 2.43, 95\% Cl 1.54 to $3.84, p<0.001)$.

Conclusions $C T$ lung cancer screening for high-risk participants presents a teachable moment for smoking cessation, especially among those who receive a positive scan result. Further behavioural research is needed to evaluate optimal strategies for integrating smoking cessation intervention with stratified lung cancer screening.

Trial registration number Results, ISRCTN 78513845

\section{INTRODUCTION}

Smoking is the leading cause of preventable morbidity and premature mortality worldwide. ${ }^{1}$ In the UK, an estimated $86 \%$ of lung cancer cases are attributable to smoking. ${ }^{2}$ The prevalence of cigarette smoking in the UK remained relatively stable between 2006 and 2014 at approximately 10 million adults $(\sim 20 \%)^{3}$ and although these rates are much lower than those of the 1970s, this declining

\section{Key messages}

What is the key question?

- What is the effect on smoking cessation of taking part in the UK randomised pilot trial of low-dose $\mathrm{CT}$ lung screening?

\section{What is the bottom line?}

- CT lung cancer screening does not appear to falsely reassure smokers or reduce their motivation to stop smoking.

\section{Why read on?}

- For clinicians and policy makers who are considering implementation of stratified (ie, high-risk) lung cancer screening, this study adds to evidence suggesting that integrating $\mathrm{CT}$ screening with evidence-based smoking cessation interventions could prompt quitting in motivated high-risk smokers.

trend has begun to plateau. ${ }^{4}$ The association between cigarette smoking and socioeconomic group is well established, with higher smoking rates among people living in more deprived areas. ${ }^{5}$

Trials have been undertaken to ascertain the effectiveness of low-dose CT screening for the earlier detection of lung cancer in high-risk groups, including smokers. ${ }^{6-9}$ The impact of CT lung screening on smoking cessation and abstinence has been examined in response to concerns that taking part in lung screening may offer a 'licence to smoke', especially for smokers who receive favourable screening results. ${ }^{10}$ Evidence from controlled trials, however, suggests that participating in lung screening significantly increases smoking cessation rates overall compared with the general population, and that receiving a positive CT screening result may provide an additional cue to action in prompting cessation. The Danish Lung Cancer Screening Trial (DLCST) reported smoking cessation rates of almost $12 \%$ in both trial arms at 1 year follow-up, compared with the Danish population rate of $4 \% .{ }^{11}$ Quit rate was significantly higher in smokers who had a positive CT result that required repeat scans. ${ }^{11}$ In the Dutch-Belgian NELSON Trial, the overall quit rate at 2 years follow-up was $16.6 \%$ compared with a background population rate of 
$3-7 \%$. Although a lower prolonged abstinence rate was observed in the screened arm (14.5\%) versus control (19.1\%), this effect disappeared following intention-to-treat (ITT) analysis, suggesting an overall positive effect of trial participation. ${ }^{12}$ A non-significant trend towards increased smoking cessation was seen in those with multiple indeterminate screening results. ${ }^{13}$ The US National Lung Screening Trial (NLST) ${ }^{14}$ found that compared with normal lung screening results, receiving any screen-detected abnormality significantly reduced the probability of continued smoking.

In addition to the moderating effect of lung screening results, demographic predictors of increased likelihood of smoking cessation have been observed in previous lung cancer screening studies. These have included older age, ${ }^{11} 1^{14}{ }^{15}$ higher socioeconomic group, ${ }^{14}$ higher education, ${ }^{12}$ being married $^{14}$ and lower nicotine dependency. ${ }^{11}{ }^{14}$ In addition, participants with higher levels of concern about lung cancer and greater perceived benefits of stopping smoking, ${ }^{10}$ and those who intend to stop smoking, ${ }^{11} 12$ are more likely to quit in the context of lung cancer screening.

The UK Lung Cancer Screening (UKLS) Pilot Trial is the first to assess the feasibility, cost-effectiveness and psychosocial impact of lung cancer screening using a single low-dose CT screen versus no screening in a UK high-risk population. ${ }^{9} 16$ The current study builds upon previous UKLS reports by examining the behavioural effects of trial participation and modifying variables on smoking cessation at short-term and long-term follow-up. It was expected that intervention arm participants would be more likely to report quitting compared with control arm participants, and that predictors of smoking cessation would include positive CT results (in screened participants), higher socioeconomic group and higher baseline distress/ concern about lung cancer.

\section{METHODS}

\section{Participants and procedures}

A random sample of 247354 individuals aged 50-75 years residing in six recruitment areas in the UK (Liverpool, Knowsley and Sefton; Cambridgeshire, Peterborough and Bedfordshire) was sent trial information packs that included a self-report questionnaire regarding lung cancer risk factors. From the questionnaire responders, 8729 patients were identified as high risk of lung cancer $(\geq 5 \%$ over 5 years) using the Liverpool Lung Project $\left(\mathrm{LLP}_{\mathrm{v} 2}\right)$ risk prediction model which includes age, sex, family history of lung cancer, smoking duration, personal history of other cancers and non-malignant respiratory diseases and exposure to asbestos. ${ }^{9}$ Characteristics of trial nonparticipants are reported elsewhere. ${ }^{17} 18$

Following completion of a second questionnaire to identify trial eligibility, those meeting the criteria were invited to attend their local recruitment centre in Liverpool or Cambridge (trial sites). High-risk individuals who gave informed written consent were randomised on a 1:1 ratio to the intervention (screening) or control arms. Randomisation used unique random personal ID codes and computer-generated sequencing for allocation concealment. ${ }^{9}$ Participants who self-reported smoking in the first questionnaire were eligible for inclusion in the current analyses. Participants in both trial arms were offered standard smoking cessation advice leaflets and given a list of local National Health Service Stop Smoking services prerandomisation.

Participants completed a touchscreen questionnaire that included baseline psychosocial measures $\left(\mathrm{T}_{0}\right)$. A second psychosocial questionnaire $\left(\mathrm{T}_{1}\right)$ was sent approximately 2 weeks after receiving either a letter of assignment to the control group or a baseline CT scan result letter (intervention arm). $\mathrm{T}_{2}$ psychosocial questionnaires were sent in a single mailshot during January 2014.

\section{Measures}

Smoking status was calculated at $\mathrm{T}_{0}$ based on self-report data within the first UKLS questionnaire. Participants were categorised into current smokers, ex-smokers and never smokers.

Smoking cessation was assessed using self-report at $\mathrm{T}_{1}$ and $\mathrm{T}_{2}$. Participants were asked whether they had quit smoking since joining UKLS, with response options 'yes', 'no', 'no but I intend to quit smoking within the next 6 months' and 'not applicable' (ie, not a smoker at baseline). Participants who responded 'no' or 'no, but intend to quit' were categorised as non-quitters. Those who responded 'not applicable' or who returned the questionnaire but missed out the smoking cessation question were categorised as non-completers.

Lung cancer distress was measured using six items adapted from Lerman et $a l^{19}$ and Watson et $a l^{20}$ to assess the frequency of lung cancer-related thoughts and their impact on mood and daily functioning. Total score range was $6-24$, with a score above 12.5 corresponding to a clinically significant threshold score on the General Health Questionnaire-28. ${ }^{21}$

Demographic variables: age and gender were obtained from medical records. Socioeconomic group was measured using Index of Multiple Deprivation ranks calculated from postcodes and categorised into standard deprivation quintiles (quintile $1=$ most deprived, quintile $5=$ least deprived). Marital group and experience of lung cancer (self and/or close others) were included in the $\mathrm{T}_{0}$ questionnaire

\section{Screening results}

Baseline CT scan results in the intervention arm included negative (normal) results, those requiring a repeat scan in 3 or 12 months, those requiring referral to the multidisciplinary team due to a major lung abnormality and significant incidental findings (such as aortic aneurisms and pneumonia but with no findings suspicious for lung cancer).

\section{Statistical analysis}

Analyses were conducted using Stata V.14. Baseline comparisons were undertaken to compare the characteristics of smokers who did and did not complete follow-up questionnaires. Participants who did not answer the smoking cessation question at $\mathrm{T}_{1}$ or $\mathrm{T}_{2}$ were imputed as smokers and included in the primary analysis of intervention effect using the ITT population, in accordance with the Russell Standard for reporting smoking cessation trials. ${ }^{22}$ Complete case sensitivity analyses were also conducted, using univariable logistic regression models fitted to the smoking cessation outcome data at $T_{1}$ and $T_{2}$ independently with an inverse probability weighting. ${ }^{23}$ Additionally, as a secondary analysis to adjust for confounders, multivariable logistic regression models were fitted to evaluate the impact of trial allocation on smoking cessation at $T_{1}$ and $T_{2}$ adjusting for $T_{0}$ lung cancer distress, sociodemographic factors (gender, age group, marital group, deprivation quintile, experience of lung cancer) and trial site. ${ }^{16}$ ORs and adjusted ORs (aORs) with 95\% CIs and $p$ values are presented. Due to multiple testing, $p<0.01$ was used to denote statistical significance.

To investigate the effect of the baseline scan result on smoking cessation, we summarised intervention arm participants into those who had a scan leading to additional clinical investigation (including repeat scan, major abnormality and incidental findings) and those receiving a negative result (ie, not requiring 
further investigation). Participants randomised to the control group were used as the reference category in order to reflect current practice. The impact of additional clinical investigation on smoking cessation at $T_{1}$ and $T_{2}$ was analysed using univariable and multivariable logistic regressions in the imputed and complete case populations. Lung cancer distress, sociodemographic factors and trial site were included in multivariable analysis.

Further subgroup analyses were carried out within the intervention arm only, involving additional univariable regression analyses to examine $T_{1}$ and $T_{2}$ smoking cessation in those receiving additional clinical investigation compared with a negative result as the reference category. We carried out this analysis to reflect a potential national policy where participants receive routine lung screening.

\section{RESULTS}

\section{Trial participation}

In total, 4061 individuals (5\% of 75958 responders to the risk questionnaire; $47 \%$ of all high-risk positive responders) attended the recruitment clinic and were consented. ${ }^{24}$ As shown in figure 1, 4055 trial participants were randomised $(n=2028$ CT intervention, $\mathrm{n}=2027$ control). $\mathrm{T}_{1}$ completion rates were $n=527 / 758(70 \%)$ for the intervention arm and $n=479 / 786$ (61\%) for the control arm, giving a total $T_{1}$ sample of $n=1006$. The non-completion rate at $\mathrm{T}_{1}$ was $\mathrm{n}=538$, of whom 231 (43\%) were intervention and $307(57 \%)$ were control participants. $T_{2}$ completion rates were $n=488 / 749$ (65\%) for the screening arm and $n=377 / 775$ (49\%) for the control arm (total $\left.\mathrm{T}_{2} \mathrm{n}=865\right)$. Of the $659 \mathrm{~T}_{2}$ non-completers, 261 (40\%) were from the intervention arm and 398 (60\%) were from the control arm.

\section{Factors associated with non-completion}

Baseline smokers in the control arm and those with experience of lung cancer were significantly less likely than those in the intervention arm to complete $\mathrm{T}_{1}$ questionnaires (see online supplementary table SI). Trial site, age, gender, marital group, deprivation and $\mathrm{T}_{0}$ lung cancer distress were not statistically significantly associated with $\mathrm{T}_{1}$ completion.

$\mathrm{T}_{2}$ questionnaire completion was significantly lower among baseline smokers in the control arm and those recruited at the Liverpool site in the most deprived quintile and with experience of lung cancer. Age, marital group, gender and baseline distress were not statistically significantly associated with $\mathrm{T}_{2}$ completion (see online supplementary table SII).

\section{Effect of trial allocation on $T_{1}$ and $T_{2}$ smoking cessation}

As shown in figure 1 , the overall $T_{1}$ trial quit rate was $111 / 1006$ (11\%). In the screening arm, 75 (14\%) individuals quit smoking at $\mathrm{T}_{1}$ and $452(86 \%)$ continued to smoke. Thirty-six individuals $(8 \%)$ in the control arm had quit smoking at $\mathrm{T}_{1}$ compared with $443(92 \%)$ who had not quit. At $\mathrm{T}_{2}$, the overall quit rate was 194/865 (22\%), with 115 screened individuals (24\%) and 79 $(21 \%)$ individuals in the control arm having quit smoking.

Primary ITT and sensitivity analyses are summarised in table 1. $\mathrm{T}_{1}$ smoking cessation was statistically significantly higher in screened individuals compared with control $(p<0.001)$ and remained statistically significant $(p=0.001)$ after adjusting for $T_{0}$ distress and all other covariates. Sensitivity analysis confirmed that $T_{1}$ smoking cessation was statistically significantly higher in the intervention group $(\mathrm{p}<0.001)$. Effects of covariates on $\mathrm{T}_{1}$ smoking cessation were not statistically significant in ITT analyses (see online supplementary table SIII): trial site $(p=0.14)$; age group compared with those under 65 years (66-70 years $\mathrm{p}=0.50$, over 70 years $\mathrm{p}=0.81)$; gender $(\mathrm{p}=0.87)$; marital group $(\mathrm{p}=0.38)$; deprivation (most vs least deprived $\mathrm{p}=0.50)$ and lung cancer experience $(p=0.45)$. There was limited evidence that participants with higher baseline lung cancer distress were more likely to quit smoking at $\mathrm{T}_{1}(\mathrm{p}=0.03)$. Similarly, covariates were non-significant in crude and adjusted complete case analyses (see online supplementary table SIV).

At $T_{2}$, there was a statistically significant difference between trial arms in quitting smoking in the crude ITT analysis $(p=0.003)$ and after adjusting for covariates $(p=0.003)$. In sensitivity analyses, the difference in cessation rate between intervention and control groups at $\mathrm{T}_{2}$ was not statistically significant $(p=0.36)$; therefore, these findings should be interpreted with caution (see table 1). The effects of other variables on $\mathrm{T}_{2}$ smoking cessation rate were not statistically significant in ITT analyses (see online supplementary table SV): trial site $(p=0.28)$; age $(66-70$ years $p=0.49$; over 70 years $p=0.18)$; gender $(p=1.18)$; marital group $(p=0.07)$; deprivation (most vs least deprived $p=0.24)$; lung cancer experience $(p=0.60)$ and baseline distress $(p=0.08)$. The effects of covariates were not statistically significant in complete case analyses at $T_{2}$ (see online supplementary table SVI).

\section{Impact of additional clinical investigation on smoking cessation}

$\mathrm{T}_{1}$ smoking cessation was reported by $16 \%$ (48/299) of participants who had additional clinical investigation following the baseline scan result and 11\% (26/227) who received a negative result. These were both compared with 8\% (36/479) who reported $\mathrm{T}_{1}$ smoking cessation in the control group. As shown in table 2 , the impact of needing additional clinical investigation on $T_{1}$ smoking cessation was statistically significant in univariable $(\mathrm{p}<0.001)$ and multivariable $(\mathrm{p}<0.001)$ analyses using the imputed population. The effect of receiving a negative result on $\mathrm{T}_{1}$ smoking cessation was not significant in univariable $(p=0.09)$ and multivariable $(p=0.09)$ analyses. Similar findings were observed in sensitivity analyses for both $\mathrm{T}_{1}$ comparisons.

At $\mathrm{T}_{2}, 30 \%$ (83/275) of participants who received additional clinical investigation following the baseline scan result and $15 \%$ $(32 / 212)$ who had negative results reported cessation. These were compared with $21 \%$ (79/377) in the control group who reported quitting at $T_{2}$. There was a statistically significant effect of additional clinical investigation on $\mathrm{T}_{2}$ smoking cessation in univariable $(p=0.007)$ and multivariable $(p=0.007)$ ITT analyses. The effect of a negative result on $\mathrm{T}_{2}$ smoking cessation was not significant in univariable $(p=0.08)$ and multivariable $(p=0.07)$ analyses; however, caution is needed when interpreting these findings. Similar results were observed in complete case analyses (see table 2).

\section{Subgroup analyses in the intervention group only}

At $T_{1}$, there was no statistically significant effect of needing additional clinical investigation on smoking cessation, compared with receiving a negative result (aOR 1.48, 95\% CI 0.89 to $2.47, \mathrm{p}=0.09$ ). At $\mathrm{T}_{2}$, there was a clear effect on smoking cessation of additional clinical investigation compared with a negative result (aOR 2.43, 95\% CI 1.54 to $3.84, \mathrm{p}<0.001$ ). Similar results were found in complete case analyses (results not shown).

\section{DISCUSSION}

Tobacco control is the major primary prevention option for lung cancer. The present study is the first to report the 


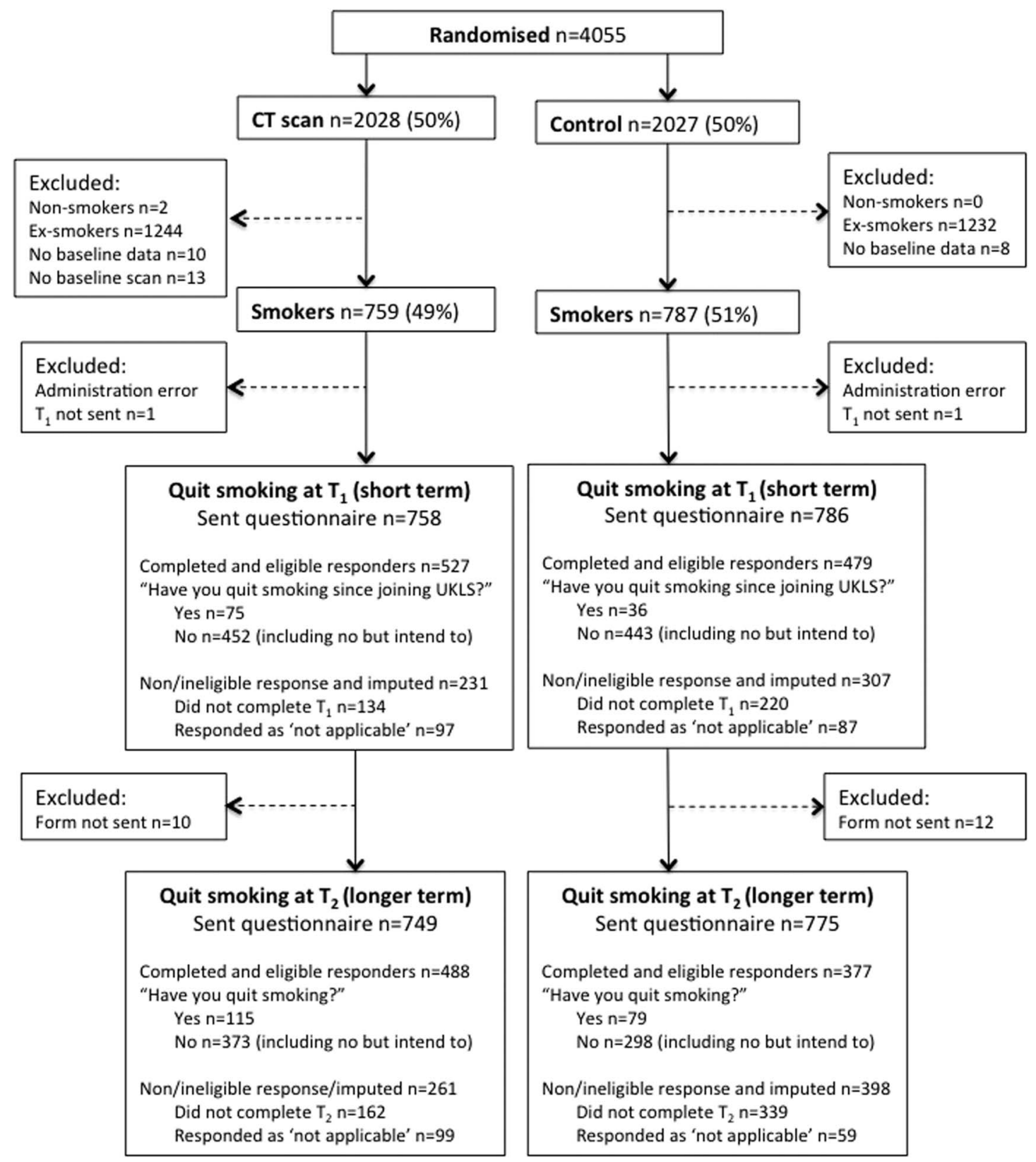

Figure 1 Trial CONSORT diagram. UKLS, UK Lung Cancer Screening.

behavioural impact of CT screening in a UK high-risk population and confirms the findings of previous trials that lung cancer screening does not falsely reassure smokers or reduce their motivation to stop smoking. The net UKLS Trial cessation rate was $11 \%$ in the short term and $22 \%$ at up to 2 years follow-up -both higher than the background cessation rate of $4 \%$ in the general UK population. For participants who underwent CT screening, the short-term quit rate of $14 \%$ was similar to that of the Dutch-Belgian NELSON Trial ${ }^{12}$ and higher than that of the DLCST. $^{11}$ Participating in the UKLS appeared to prompt smoking cessation overall, with a differential and positive effect of lung screening at short-term and longer-term follow-up. While a degree of caution is needed due to imputation of missing responders as smokers, ${ }^{22}$ the present findings indicate that smoking cessation was higher in the intervention arm and that engaging in CT lung cancer screening increased the likelihood of stopping smoking in the longer term. Despite concerns about a negative lung screen offering a 'licence to smoke', ${ }^{10}$ there was no evidence that UKLS screening participants who received an all-clear CT result were less likely to quit. Analysis indicated that a positive CT scan result prompted smoking cessation in the longer term compared with participants who were not screened and participants who received a negative scan, suggesting that a positive lung screening result may provide an additional stimulus for quitting over and above that of screening participation. This mirrors the findings of other controlled trials, including the DLCST ${ }^{11}$ and US NLST, ${ }^{14}$ where smokers with identified abnormalities were more likely to stop smoking than those with normal results.

The current evidence suggests that an integrated package of CT lung screening and smoking cessation support has the potential to expedite quitting in smokers who are motivated and receptive. The voluntary nature of the trial meant that smokers who took part were self-selected and may already have been 
Table 1 Effect of trial allocation on $\mathrm{T}_{1}$ and $\mathrm{T}_{2}$ smoking cessation

\begin{tabular}{|c|c|c|c|c|}
\hline \multicolumn{5}{|c|}{ Quit smoking at $T_{1}(n=1544)$} \\
\hline Primary analysis* & Yes $(n=111)$ & No $(n=1433)$ & Univariable OR $(95 \% \mathrm{Cl})$ & Multivariable $\mathrm{OR}+(95 \% \mathrm{Cl})$ \\
\hline Intervention, n (\%) & $75(68 \%)$ & $683(48 \%)$ & 2.29 (1.52 to 3.45$)$ & 2.38 (1.56 to 3.64$)$ \\
\hline Control, n (\%) & $36(32 \%)$ & $750(52 \%)$ & & \\
\hline Sensitivity analysis $\ddagger$ & Yes $(n=111)$ & No $(n=895)$ & Univariable OR $(95 \% \mathrm{Cl})$ & Multivariable $\mathrm{OR}+(95 \% \mathrm{Cl})$ \\
\hline Intervention, n (\%) & $75(68 \%)$ & $452(50 \%)$ & 2.04 (1.34 to 3.10$)$ & 2.09 (1.36 to 3.23$)$ \\
\hline Control, n (\%) & $36(32 \%)$ & $443(50 \%)$ & & \\
\hline \multicolumn{5}{|c|}{ Quit smoking at $T_{2}(n=1524)$} \\
\hline Primary analysis* & Yes $(n=194)$ & No $(n=1330)$ & Univariable OR $(95 \% \mathrm{Cl})$ & Multivariable $\mathrm{OR}+(95 \% \mathrm{Cl})$ \\
\hline Intervention, $\mathrm{n}(\%)$ & $115(59 \%)$ & $634(48 \%)$ & 1.60 (1.18 to 2.17$)$ & 1.60 (1.17 to 2.18$)$ \\
\hline Control, n (\%) & $79(41 \%)$ & $696(52 \%)$ & & \\
\hline Sensitivity analysis $¥$ & Yes $(n=194)$ & No $(n=671)$ & Univariable OR $(95 \% \mathrm{Cl})$ & Multivariable OR† $(95 \% \mathrm{Cl})$ \\
\hline Intervention, $\mathrm{n}(\%)$ & $115(59 \%)$ & $373(55 \%)$ & $1.16(0.84$ to 1.61$)$ & $1.16(0.65$ to 1.33$)$ \\
\hline Control, n (\%) & $79(41 \%)$ & $298(45 \%)$ & & \\
\hline
\end{tabular}

${ }^{*}$ Intention-to-treat (ITT) analyses with the imputed population.

tAdjusted for $\mathrm{T}_{0}$ cancer distress, recruitment site, gender, age, marital group, deprivation and experience of lung cancer.

‡Complete case analyses.

contemplating quitting. ${ }^{25}$ It is difficult, therefore, to directly attribute smoking cessation to UKLS participation, although Ostroff $e t a l^{10}$ reported that smokers who quit after CT lung screening ascribed their decision to screening participation. In the current trial, we observed a marginal trend towards higher baseline distress in those who reported quitting in the short term, which suggests that experiencing a degree of concern about lung cancer may be necessary to galvanise smoking cessation. However, we did not directly assess baseline quit intentions, and future evaluations of CT lung screening would therefore benefit from examining the influence of both mood-related and smoking-related cognitions on behavioural outcomes.

The limitations of sample size and study design are acknowledged. The UKLS Trial was not specifically designed to test the effects of lung screening combined with smoking cessation support; hence, the types of stop-smoking interventions accepted by participants were not recorded, nor were comparative data available on cessation rates in the Liverpool and Papworth regions during the life of the trial. It was not possible to ascertain the moderating role of nicotine dependence or biochemically validate self-reported smoking behaviour; therefore, the current findings should be interpreted cautiously due to the sole use of self-reported cessation. Nevertheless, the present study adds to growing evidence that integrating CT lung screening with evidence-based smoking cessation interventions could prompt quitting in motivated high-risk smokers. While our sample was not sufficiently large to examine continued smoking abstinence in those who reported quitting at short-term follow-up, the NELSON Trial indicated that combining low-dose CT screening with smoking cessation advice led to sustained abstinence. ${ }^{12}$ Most smokers enrolling in CT lung screening studies are motivated to quit; therefore, it will be critical to evaluate actual quit rates prompted by screening and whether they are maintained over time in the context of a lung screening health service. We found that longer-term study retention was less likely in smokers who were from socioeconomically deprived areas and who had experience of lung cancer. Evidence from other studies suggests that these high-risk groups may be deterred from lung screening due to fearful and fatalistic beliefs about lung cancer outcomes, ${ }^{26-28}$ stigma and

Table 2 Impact of baseline scan result on $T_{1}$ and $T_{2}$ smoking cessation

\begin{tabular}{|c|c|c|c|c|c|}
\hline \multicolumn{2}{|c|}{ Baseline scan result } & Quit smoking & Total & Univariable OR $(95 \% \mathrm{Cl})$ & Multivariable $\mathrm{OR}^{*}(95 \% \mathrm{Cl})$ \\
\hline \multicolumn{6}{|c|}{ Primary analysis $\uparrow$} \\
\hline $\mathrm{T}_{1}$ & $\begin{array}{l}\text { Control group } \\
\text { Negative result } \neq \\
\text { Additional investigation } \neq\end{array}$ & $\begin{array}{l}36 \\
26 \\
48\end{array}$ & $\begin{array}{l}786 \\
340 \\
416\end{array}$ & $\begin{array}{l}\text {-Reference- } \\
1.73(1.02 \text { to } 2.91) \\
2.72(1.73 \text { to } 4.26)\end{array}$ & $\begin{array}{l}\text {-Reference- } \\
1.78(1.04 \text { to } 3.05) \\
2.85(1.79 \text { to } 4.53)\end{array}$ \\
\hline $\mathrm{T}_{2}$ & $\begin{array}{l}\text { Control group } \\
\text { Negative result } \neq \\
\text { Additional investigation } \neq\end{array}$ & $\begin{array}{l}79 \\
32 \\
83\end{array}$ & $\begin{array}{l}775 \\
338 \\
409\end{array}$ & $\begin{array}{l}\text {-Reference- } \\
0.92(0.60 \text { to } 1.42) \\
2.24(1.60 \text { to } 3.14)\end{array}$ & $\begin{array}{l}\text {-Reference- } \\
0.90(0.58 \text { to } 1.40) \\
2.29(1.62 \text { to } 3.22)\end{array}$ \\
\hline \multicolumn{6}{|c|}{ Sensitivity analysis§ } \\
\hline $\mathrm{T}_{1}$ & $\begin{array}{l}\text { Control group } \\
\text { Negative result } \\
\text { Additional investigation }\end{array}$ & $\begin{array}{l}36 \\
26 \\
48\end{array}$ & $\begin{array}{l}479 \\
227 \\
299\end{array}$ & $\begin{array}{l}\text {-Reference- } \\
1.59(0.94 \text { to } 2.71) \\
2.35(1.49 \text { to } 3.72)\end{array}$ & $\begin{array}{l}\text {-Reference- } \\
1.61(0.93 \text { to } 2.77) \\
2.46(1.53 \text { to } 3.96)\end{array}$ \\
\hline $\mathrm{T}_{2}$ & $\begin{array}{l}\text { Control group } \\
\text { Negative result } \\
\text { Additional investigation }\end{array}$ & $\begin{array}{l}79 \\
32 \\
83\end{array}$ & $\begin{array}{l}377 \\
212 \\
275\end{array}$ & $\begin{array}{l}\text {-Reference- } \\
0.67(0.43 \text { to } 1.05) \\
1.63(1.14 \text { to } 2.33)\end{array}$ & $\begin{array}{l}\text {-Reference- } \\
0.65(0.41 \text { to } 1.04) \\
1.66(1.15 \text { to } 2.39)\end{array}$ \\
\hline
\end{tabular}

${ }^{*}$ Adjusted for $\mathrm{T}_{0}$ cancer distress, recruitment site, gender, age, marital group, deprivation and experience of lung cancer.

tIntention-to-treat (ITT) analyses with the imputed population.

$\ddagger$ One participant removed due to protocol deviation.

$\S$ Complete case analyses. 
scepticism. ${ }^{29-31}$ The consistent association between smoking, deprivation and lower screening uptake is a problem for public health that must be addressed in future lung screening.

Implementation of a UK national lung cancer screening programme for high-risk groups offers opportunities for smoking cessation at multiple points in the screening process, from the initial screening invitation to CT scanning and disclosure of results. ${ }^{10}$ Smoking cessation counselling combined with pharmacotherapy is effective ${ }^{32-34}$ and could be successfully implemented in the lung screening setting. ${ }^{35}$ However, further behavioural research is needed to identify ways of engaging harder to reach smokers and to robustly test the optimal type and timing of strategies for delivering stop-smoking support to high-risk participants. Successful integration of evidence-based strategies for smoking cessation with stratified lung cancer screening could be a prudent use of limited healthcare resources, translating into major health benefits for all smoking-related diseases.

\section{Author affiliations \\ 'Division of Population Medicine, Cardiff University School of Medicine, Cardiff, UK \\ ${ }^{2}$ Department of Biostatistics and Health Informatics, Institute of Psychiatry, \\ Psychology and Neuroscience, King's College London, London, UK \\ ${ }^{3}$ Royal Brompton and Harefield NHS Trust, London, UK \\ ${ }^{4}$ Department of Respiratory Medicine, Nottingham University Hospitals, Nottingham, UK \\ ${ }^{5}$ Queen Mary University of London, London, UK \\ ${ }^{6}$ Roy Castle Lung Cancer Research Programme, Department of Molecular and \\ Clinical Cancer Medicine, University of Liverpool, Liverpool, UK}

\section{Twitter Follow Kate Brain @Katebrain}

Acknowledgements We wish to thank Bev Green for her invaluable contribution to trial administration, Fiona McRonald and Ghasem Yadegarfar for assisting with trial data collection and the trial participants who gave their time in completing questionnaires. We acknowledge the wider UKLS management team: Tim Eisen, David Hansell, John Holemans, Terry Kavanagh, Keith Kerr, Martin Ledson, Arjun Nair, Richard Page, Mahesh Parmar, Robert Rintoul, Nicholas Screaton, Nicholas Wald, David Weller, David Whynes and Paula Williamson.

Contributors $\mathrm{KB}$ - trial conception and design, data analysis, data interpretation, manuscript preparation. $\mathrm{BC}$-trial statistician, statistical analysis, data interpretation, manuscript review. KJL-data collection, data analysis, data interpretation, manuscript review. $O B$ - data analysis and interpretation, manuscript review. $A D-$ radiological review, data interpretation and manuscript review. DRB - trial design, UKLS care pathway, data interpretation, manuscript review. SD—trial design, data interpretation, manuscript review. JKF-trial conception and design, data interpretation, manuscript review.

Funding NIHR Health Technology Assessment (HTA) programme. The views and opinions expressed therein are those of the authors and do not necessarily reflect those of NIHR HTA, National Health Service or the Department of Health.

Competing interests None declared.

Patient consent Obtained.

Ethics approval Ethical approval for the study was given by Liverpool Central research ethics committee in December 2010 (reference number 10/H1005/74). All UKLS participants provided informed consent before taking part. The trial was registered with the International Standard Randomised Controlled Trial Register (ISRCTN) under the reference 78513845 .

Provenance and peer review Not commissioned; externally peer reviewed.

Open Access This is an Open Access article distributed in accordance with the terms of the Creative Commons Attribution (CC BY 4.0) license, which permits others to distribute, remix, adapt and build upon this work, for commercial use, provided the original work is properly cited. See: http://creativecommons.org/licenses/ by/4.0/

\section{REFERENCES}

1 World Lung Foundation/American Cancer Society. The tobacco atlas. http://www. tobaccoatlas.org (accessed 18 Mar 2016).

2 Cancer Research UK. Lung cancer risk factors. http://www. cancerresearchuk.org/ health-professional/cancer-statistics/statistics-by-cancer-type/lung-cancer/risk-factors (accessed 18 Mar 2016).
3 ASH. Smoking statistics. http://www.ash.org.uk/files/documents/ASH_93.pdf (accessed 18 Mar 2016).

4 ASH. Smoking statistics: who smokes and how much. http://ash.org.uk/files/ documents/ASH 106.pdf (accessed 18 Mar 2016).

5 Office for National Statistics. Do smoking rates vary between more and less advantaged areas? http://www.ons.gov.uk/ons/rel/disability-and-health-measurement/ do-smoking-rates-vary-between-more-and-less-advantaged-areas-/2012/ sty-smoking-rates.html (accessed 18 Mar 2016).

6 van Klaveren RJ, Oudkerk M, Prokop $\mathrm{M}$, et al. Management of lung nodules detected by volume CT scanning. N Eng/ J Med 2009;361:2221-9.

7 Pedersen J, Ashraf H, Dirksen A, et al. The Danish randomized lung cancer CT screening trial—overall design and results of the prevalence round. J Thorac Oncol 2009:5:608-14

8 Aberle DR, Adams AM, Berg CD, et al. Reduced lung cancer mortality with low-dose computed tomographic screening. N Engl J Med 2011;365:395-409.

9 Field JK, Duffy SW, Baldwin DR, et al. United Kingdom Lung Cancer RCT Pilot Screening Trial (UKLS): baseline findings from the screening arm provide evidence for a cost effective exemplar for implementation of lung cancer screening. Thorax 2016;71:161-70.

10 Ostroff JS, Buckshee N, Mancuso CA, et al. Smoking cessation following CT screening for early detection of lung cancer. Prev Med 2001;33:613-21.

11 Ashraf $H$, Tønnesen $\mathrm{P}$, Holst Pedersen J, et al. Effect of $\mathrm{CT}$ screening on smoking habits at 1-year follow-up in the Danish Lung Cancer Screening Trial (DLCST). Thorax 2009:64:388-92.

12 van der Aalst $C M$, van den Bergh KA, Willemsen MC, et al. Lung cancer screening and smoking abstinence: 2 year follow-up data from the Dutch-Belgian randomised controlled lung cancer screening trial. Thorax 2010;65:600-5.

13 van der Aalst $C M$, van Klaveren RJ, van den Bergh $\mathrm{KA}$, et al. The impact of a lung cancer computed tomography screening result on smoking abstinence. Eur Respir $J$ 2011;37:1466-73.

14 Tammemägi $M C$, Berg $C D$, Riley $T L$, et al. Impact of lung cancer screening results on smoking cessation. J Natl Cancer Instit 2014;106(6):dju084.

15 Townsend $\mathrm{CO}$, Clark MM, Jett JR, et al. Relation between smoking cessation and receiving results from three annual spiral chest computed tomography scans for lung carcinoma screening. Cancer 2005;103:2154-62.

16 Brain K, Lifford KJ, Carter B, et al. Long-term psychosocial outcomes of low dose computed tomography screening: results of the UK Lung Cancer Screening (UKLS) randomised controlled trial. Thorax 2016;71:996-1005.

17 McRonald F, Yadegarfar G, Baldwin D, et al. The UK Lung Screen (UKLS): demographic profile of first 88,897 approaches provides recommendations for population screening. Cancer Prev Res 2014;7:362-71.

18 Ali N, Lifford KJ, Carter B, et al. Barriers to uptake among high-risk individuals declining participation in lung cancer screening: a mixed-methods analysis of the United Kingdom Lung Cancer Screening (UKLS) trial. BMJ Open 2015;5:e008254.

19 Lerman C, Daly M, Sands C. Mammography adherence and psychological distress among women at risk for breast cancer. J Nat/ Cancer Inst 1993;85:1074-80.

20 Watson M, Lloyd S, Davidson J, et al. The impact of genetic counselling on risk perception and mental health in women with a family history of breast cancer. Brit J Cancer 1999;79:868-74.

21 Brain $\mathrm{K}$, Parsons E, Bennett $\mathrm{P}$, et al. The evolution of worry after breast cancer risk assessment: 6-year follow-up of the TRACE study cohort. Psychooncol 2011;20:984-91.

22 West $\mathrm{R}$, Hajek $\mathrm{P}$, Stead $\mathrm{L}$, et al. Outcome criteria in smoking cessation trials: proposal for a common standard. Addiction 2005;100:299-303.

23 Seaman SR, White IR. Review of inverse probability weighting for dealing with missing data. Stat Methods Med Res 2013;22:278-95.

24 Field JK, Duffy SW, Baldwin DR, et al. The UK Lung Cancer Screening Trial: a pilot randomised controlled trial of low-dose computed tomography screening for the early detection of lung cancer. Health Technol Assess 2016;20:1-146.

25 DiClemente CC, Prochaska JO, Fairhurst SK, et al. The process of smoking cessation: an analysis of precontemplation, contemplation, and preparation stages of change. J Cons Clin Psychol 1991;59:295-304.

26 Jonnalagadda S, Bergamo C, Lin JJ, et al. Beliefs and attitudes about lung cancer screening among smokers. Lung Cancer 2012;77:526-31.

27 Patel D, Akporobaro A, Chinyanganya N, et al. Attitudes to participation in a lung cancer screening trial: a qualitative study. Thorax 2013;67:418-25.

28 Quaife SL, McEwen A, Janes SM, et al. Smoking is associated with pessimistic and avoidant beliefs about cancer: results from the International Cancer Benchmarking Partnership. Br J Cancer 2015;112:1799-804.

29 Silvestri GA, Nietert PJ, Zoller J, et al. Attitudes towards screening for lung cancer among smokers and their non-smoking counterparts. Thorax 2007:62:126-30.

30 van den Bergh KAM, Essink-Bot ML, van Klaveren RJ, et al. Informed participation in a randomised controlled trial of computed tomography screening for lung cancer. Eur Respir J 2009:34:711-20

31 Quaife SL, Marlow LA, McEwen A, et al. Attitudes towards lung cancer screening in socioeconomically deprived and heavy smoking communities: informing sereening communicatiom. Health Expect. Zoubtischeosobnling. First: 11 Jul 2016. doi:10.1111/hex.12481. 


\section{Lung cancer}

32 Hiscock R, Murray S, Brose LS, et al. Behavioural therapy for smoking cessation: the effectiveness of different intervention types for disadvantaged and affluent smokers. Addict Behav 2013;38:2787-96.

33 Free C, Knight R, Robertson S, et al. Smoking cessation support delivered via mobile phone text messaging (txt2stop): a single-blind, randomised trial. Lancet 2011;378:49-55.
34 Hajek P, Stead LF, West R, et al. Relapse prevention interventions for smoking cessation. Cochrane Database Syst Rev 2013;8:CD003999.

35 Piñeiro B, Simmons VN, Palmer AM, et al. Smoking cessation interventions within the context of Low-Dose Computed Tomography lung cancer screening: a systematic review. Lung Cancer 2016;98:91-8. 